UCRL-CR-133199

PPG99-003

\title{
Criteria Evaluation for Cleanliness Testing Phase 0
}

Michael Meltzer

Carolyn Koester

Chris Steffani

February 4, 1999

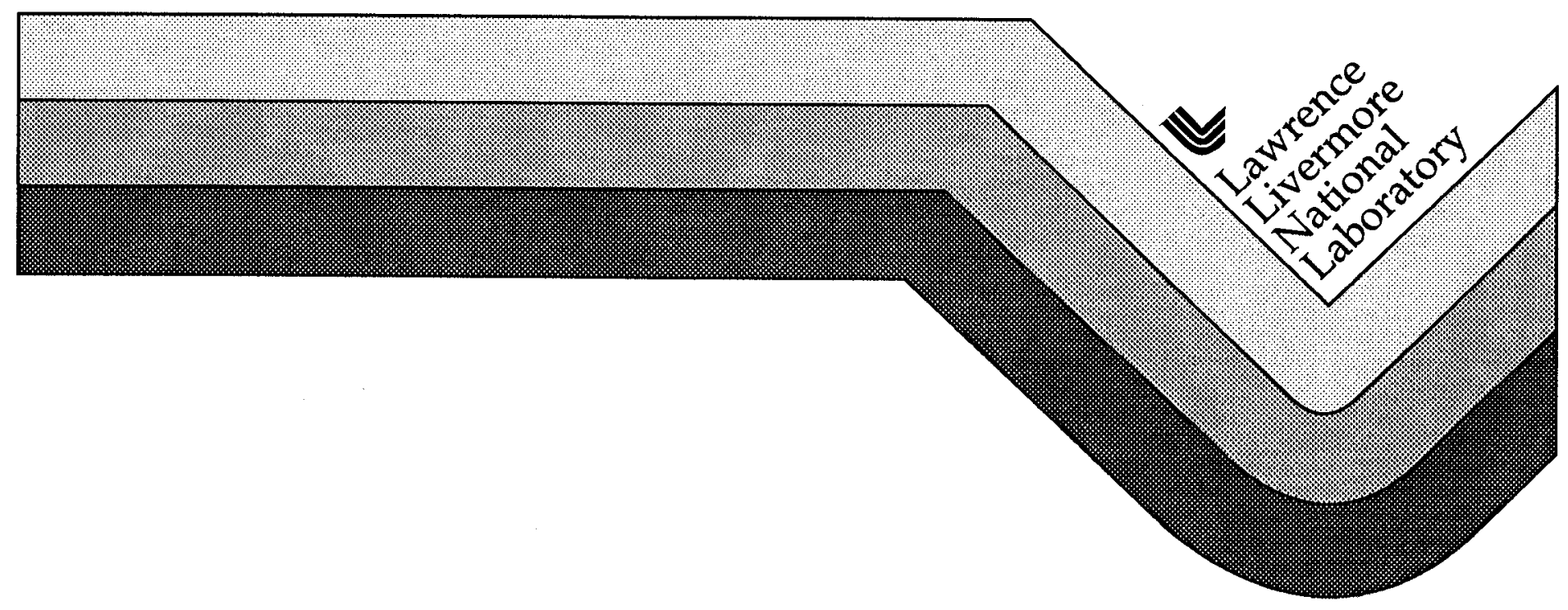




\section{DISCLAIMER}

This document was prepared as an account of work sponsored by an agency of the United States Government. Neither the United States Government nor the University of Califomia nor any of their employees, makes any warranty, express or implied, or assumes any legal liability or responsibility for the accuracy, completeness, or usefulness of any information, apparatus, product, or process disclosed, or represents that its use would not infringe privately owned rights. Reference herein to any specific commercial product, process, or service by trade name, trademark, manufacturer, or otherwise, does not necessarily constitute or imply its endorsement, recommendation, or favoring by the United States Government or the University of California. The views and opinions of authors expressed herein do not necessarily state or reflect those of the United States Govemment or the University of Califomia, and shall not be used for advertising or product endorsement purposes.

Work performed under the auspices of the U.S. Department of Energy by Lawrence Livermore National Laboratory under Contract W-7405-ENG-48. 
Project Report

for

The Boeing Company

Defense and Space Group

Criteria Evaluation for Cleanliness Testing

Phase 0

Project Number $\mathbf{L 7 6 5 3}$

Prepared by

\section{Lawrence Livermore National Laboratory}

\section{Michael Meltzer, Environmental Protection Department \\ Carolyn Koester, Chemistry and Material Sciences \\ Chris Steffani, Mechanical Engineering}

\subsection{Project Summary}

The Boeing Company (Boeing) contracted with Lawrence Livermore National Laboratory (LLNL) to develop criteria for evaluating the efficacy of its parts cleaning processes. In particular, LLNL and Boeing are attempting to identify levels of contamination that lead to parts failures. Sufficient contamination to cause impairment of anodizing, alodining, painting, or welding operations is considered a "part failure."

In the "Phase 0" part of the project that was recently completed, preliminary analyses of aluminum substrates were performed as a first step in determining suitable cleanliness criteria for actual Boeing parts made from this material. A wide spread of contamination levels was specified for the Phase 0 test coupons, in the hopes of finding a range in which an appropriate cleanliness specification might lie. It was planned that, based on the results of the Phase 0 testing, further more detailed analyses ("Phase 1 
testing") would be performed in order to more accurately identify the most appropriate criteria.

For the Phase 0 testing, Boeing supplied LLNL with $3^{\prime \prime} \times 6^{\prime \prime}$ and $3^{\prime \prime} \times$ 10" aluminum test panels which LLNL contaminated with measured amounts of typical hydrocarbon substances encountered in Boeing's fabrication operations. The panels were then subjected by Boeing to normal cleaning procedures, after which they went through one of the following sets of operations:

- anodizing and primer painting

- alodining (chromating) and primer painting

- welding

The coatings or welds were then examined by both Boeing and LLNL to determine whether any of the operations were impaired, and whether there was a correlation between contamination level and damage to the parts. The experimental approach and results are described in detail in the following sections.

\subsection{Work Plan}

The various steps in this project are summarized below.

Step 1: Test Panel and Contaminant Preparation: Boeing prepared 240 test coupons from aluminum alloy 6061-T4. Panels were cut from aluminum sheets $\left(48^{\prime \prime} \times 144^{\prime \prime}\right)$, with grain direction along the major axis of each panel. Both 0.063" and 0.125" aluminum stock was used. Of the panels, 170 had dimensions of $0.063^{\prime \prime} \times 3^{\prime \prime} \times 10^{\prime \prime}$, while 70 had dimensions of $0.125^{\prime \prime} \times 3^{\prime \prime} \times 10^{\prime \prime}$.

Boeing also supplied a contaminant mixture containing equal amounts of Blasocut 4000, CutMax 570, TrimTap Light, Meropa 460, and Boelube 70106 .

Step 2: Test Panel Contamination: As per Boeing's instructions, LLNL coated $20 \%$ of the panels of each size with $0.03 \mathrm{mg} / \mathrm{ft}^{2}$ of the contaminant mixture, $20 \%$ with 10 times this concentration, $20 \%$ with 100 times this concentration, and $20 \%$ with 1,000 times this concentration. $20 \%$ of the panels were also left uncontaminated, to 
establish a baseline measurement (i.e. to serve as blank control experiments). The coating requirements are tabulated in Table 1.

\section{Table 1: Contamination Level Requirements}

Contamination Level
No contamination
$0.03 \mathrm{mg} / \mathrm{t}^{2}$
$0.3 \mathrm{mg} / \mathrm{t}^{2}$
$3 \mathrm{mg} / \mathrm{ft}^{2}$
$30 \mathrm{mg} / \mathrm{ft}^{2}$
Total

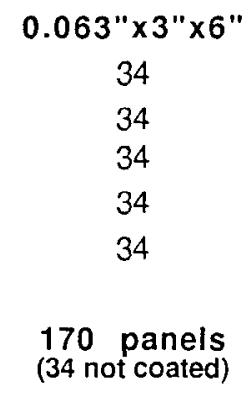
$0.125 " \times 3 " \times 6 "$
14
14
14
14
14
70 panels
(14 not coated)

Step 3: Processing Panels: LLNL kept 2 panels from each group for contamination analysis (for a total of 20 panels). The remaining 220 panels were sent to Boeing. Boeing subjected each of the LLNLcontaminated panels to its standard cleaning and surface preparation operations, after which the panels were processed according to the following schedule, shown in Table 2 .

\section{Table 2: Processing Schedule}

$\begin{array}{lcccccc}\text { Contamination Level } & \begin{array}{c}\text { Anodize } \\ \text { Only }\end{array} & \begin{array}{c}\text { Alodine } \\ \text { Prime }\end{array} & \begin{array}{c}\text { Alodine } \\ \text { Only }\end{array} & \begin{array}{c}\text { Alodine } \\ \text { Prime }\end{array} & \text { Weld } & \text { Total } \\ \text { No contamination } & 10 & 6 & 10 & 6 & 12 & 44 \\ 0.03 \mathrm{mg} / \mathrm{ft} 2 & 10 & 6 & 10 & 6 & 12 & 44 \\ 0.3 \mathrm{mg} / \mathrm{ft} 2 & 10 & 6 & 10 & 6 & 12 & 44 \\ 3 \mathrm{mg} / \mathrm{ft} 2 & 10 & 6 & 10 & 6 & 12 & 44 \\ 30 \mathrm{mg} / \mathrm{ft} 2 & 10 & 6 & 10 & 6 & 12 & 44 \\ \text { TOTAL } & 50 & 30 & 50 & 30 & 60 & 220\end{array}$

Note: Pairs of panels from each group were welded together

Step 4: Evaluation of Panels: Panels processed by Boeing were subjected by both Boeing and LLNL to salt spray, adhesion, and weld porosity tests, in order to determine, if possible, a relation between contamination levels and part failure of the panels. In addition, LLNL analyzed the 20 panels not shipped to Boeing by gas 
chromatographic mass spectrometry (GC/MS) in order to examine surface residues. Table 3 summarizes the evaluation steps.

\section{Table 3: Panel Evaluation}

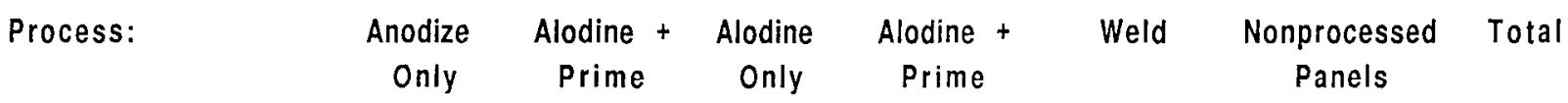

Evaluation Technique: Salt Spray Adhesion Salt Spray Adhesion Weld Porosity GC/MS

Boeing Evaluated

LLNL Evaluated

TOTAL

$\begin{array}{lll}25 & 15 & 25 \\ 25 & 15 & 25 \\ 50 & 30 & 50\end{array}$

$30 \quad 50$

$\begin{array}{ll}25 & 15 \\ 25 & 15 \\ 50 & 30\end{array}$

30

30

60
110

130

240

\subsection{Details of Test Panel Contamination}

\subsection{Developing the Coating Method}

It was clear that it would be necessary to dissolve the contaminant mixture in a solvent in order for it to be applied evenly and in the required concentrations to a surface. Thus, we first identified the best solvents in which to dissolve the Boeing contaminants. The following solvents were examined:

- dichloromethane

- methanol

- isopropanol

- ethylacetate

- acetone

- hexane

- methyl-tert-butyl ether

- methanol/dichloromethane

- methyl-tert-butyl ether/methanol

- toluene/acetone

- isopropanol/dichloromethane

- acetone/dichloromethane

- n-methylpyrrolidinone 
None of these solvents completely dissolved all of the components of the Boeing contaminant mixture. The methanol/dichloromethane and isopropanol/dichloromethane, however, kept the undissolved oil components suspended in solution long enough to allow spraying of the mixture on the plates.

$\mathrm{N}$-methylpyrrolidinone is used as a dichloromethane replacement in many industrial processes. While this solvent did a good job of dissolving the contaminant mixture, the long length of time needed for this solvent to evaporate prevented its use. The methanol/dichloromethane mixture was eventually selected as the best solvent combination to use.

Several coating methods were evaluated before finally deciding to use a spray nebulizer approach. The first method examined was dissolution of a known amount of contaminant mixture in a known amount of solvent followed by application directly to the test plate. This approach, in which the test plate has a depression machined in it to contain the contaminant-solvent mix, is used in other LLNL projects. Because Boeing test plates were flat, we surrounded the plates with a silicone frame to prevent the solvent from leaking off the plate. The aim was to evaporate the volatile solvent from the plate, leaving an even deposit of the non-volatile contaminant mix on the test plates. However, this method did not work well with the Boeing contaminant mix. Several oil components precipitated from solution before the solvent dried, resulting in a nonuniform oil coating on the plates.

Because of the above issues, we decided to develop a method for uniformly spraying the contaminant mix on the test plates. A partner on another project, Thiokol Aerospace and Industrial Technologies, has successfully implemented an ultrasonic spray nebulizer (48 kHz microspray from Sono-Tek Corporation, Highland, New York) into an automated system designed to coat contaminants onto test plates.' However, because this system costs in excess of

'Precision Contamination Application Using Ultrasonic Spray Technology, Odell Huddleston, Jr., Thiokol Corporation (Huntsville, Alabama office), document TWR-65882, December 1994. 
$\$ 30,000$, it was beyond the budget of this project. We investigated the use of a Badger airbrush as a cost-effective approach to coating test panels. While we could reproducibly deposit half gram quantities of solvent on test panels with relative standard deviations of the mass of solvent deposited ranging from $15 \%$ to $40 \%$, the airbrush was cumbersome to use. Uniform coating of a test plate, as well as the size of the solvent droplets deposited on the plate's surface, was dependent on the distance of the airbrush from the surface, the width of the airbrush aperture (which was not easy to control precisely), and the position of the pneumatic control for the airbrush. Thus, there were many variables in this system that were difficult to control.

Because mechanical spraying had the potential for uniform deposition of the contaminant mix on the plate surface, we decided to pursue its use in another configuration, employing a nebulizer instead of an airbrush. The apparatus developed for the coating process consisted of a glass nebulizer manufactured by Precision Glass Blowing of Colorado (Type C, MLPM $=2$, PSI $=30$ ) connected with $1 / 8$ " Teflon tubing to a syringe pump (Model 100, KD Scientific). Small pieces of Tygon tubing and cable ties attached the Teflon tubing to the nebulizer and to the $50 \mathrm{~mL}$ glass syringe (Micro-Mate ${ }^{\circledR}$, Popper and Sons) that served as a solvent reservoir. Air from a small compressor caused aerosol formation as the solvent left the nebulizer. Typical operating conditions included a solvent flow rate of $2 \mathrm{~mL} /$ minute and a nebulization gas pressure of 10 PSI of air.

The contaminants were introduced into the nebulizer in a $50 / 50$ $(\mathrm{v} / \mathrm{v})$ solution of dichloromethane (Burdick and Jackson, gas chromatography (GC) grade) and methanol (Burdick and Jackson, high purity solvent grade). Panel coating took place as the panels, which were held in a plastic holder, were moved by hand under the stationary nebulizer for 30 seconds. The nebulizer was located $7 \mathrm{~cm}$ above the panel surface. Care was taken to ensure uniform coating of the panels.

Given the concentration of contaminant mixture in solution, the flow rate, coating time, area of surface being coated, and efficiency with which the contaminant mixture was deposited on the panels, the amount of contaminant mixture deposited on the surface of the test Project Summary Rev 9 
panels could be calculated. For several reasons, this system was much easier to use than the airbrush. Because the nebulizer had a fixed-size aperture, the problems associated with the variable width of the airbrush aperture were not encountered. Also, solvent flow rate to the nebulizer and air pressure could be precisely controlled.

\subsection{Deposition Efficiency Calculation for Nebulizer System}

Experiments were performed to determine the efficiency with which the test plates were coated with a contaminant. In the first experiment, a known concentration of octanol (a relatively nonvolatile compound) was dissolved in $50 / 50 \quad(\mathrm{v} / \mathrm{v})$ methanol/dichloromethane. This solution was sprayed, using the LLNL nebulizer system, onto aluminum test panels. The octanol was then removed from the test panels with a rinse of dichloromethane. The amount of octanol in this rinse was measured by gas chromatographic mass spectrometry. The amount of octanol that should have been deposited on the test plates (i.e. the $100 \%$ efficiency number) was determined by considering the concentration of octanol in solution, the length of time that the spray was applicd to the plate, and the flow rate of the pump. By comparing the measured amount of octanol on the test plate (assuming that all of the octanol was removed by the dichloromethane rinse) and the amount of octanol that was expected to be deposited on the plates, the actual coating efficiency was calculated. In this experiment, $42 \%$ of the octanol that was sprayed was deposited on the test plate. Contaminant losses might be caused by small aerosol droplets being removed by airflow through the chemical hood in which coating is performed. Spray-coating efficiency might also be compound dependent. For the plates that were coated with the mix of Boeing contaminants, on average $(n=6) \quad 36 \%$ of the contaminants sprayed from the nebulizer reached the plate surface.

\subsection{Analysis of Contaminants}

The Boeing contaminant mix contains equal amounts of Blasocut 4000, CutMax 570, TrimTap Light, Meropa 460, and Boelube 70106. LLNL's Contamination Analysis Unit (CAU), a portable instrument employing mass spectrometry to analyze surface contamination, was used to determine the mass spectrum for the contaminant mix. The 
dominant ions present in the mass spectrum of this contaminant mix were $m / z 55,57,67,71,77,81,95,97,109$, and 111 .

A mass spectrum for each of the individual components of the contaminant mix was also determined with the CAU. The contaminant mix and the individual components exhibited similar spectra that were nearly indistinguishable with the CAU. Some minor differences in the mass spectra of the contaminants, however, were observed. CutMax 570 has a greater intensity of $\mathrm{m} / \mathrm{z} 65$ and 77 than is present in the mixture. Boelube 70106 has a cluster of ions at $\mathrm{m} / \mathrm{z} 137,138,139$, and 140 that are not present in the other individual contaminants. Blasocut 4000 has a characteristic ion at $\mathrm{m} / \mathrm{z} 59$, which disappears at temperatures greater than $100^{\circ} \mathrm{C}$. TrimTap Light has a unique ion at $m / z$ 135. Meropa 460 is a very viscous nonvolatile oil -- no ions above background could be detected from this material with the CAU. From the above results, it appears feasible that the CAU could be used to monitor part surfaces for residues of the Boeing contaminant mix (with the exception of Meropa 460).

\subsection{Verification of Coating Methodology}

Once the panels were coated according to the schedule in Table 1, two panels were removed from each group and used to verify that the coating process worked as expected. While we had originally planned to use the CAU to verify the successful coating of the test panels, the CAU was undergoing repairs at the time, and so verification of analyte coating concentrations was performed using GC/MS. The remaining panels, along with blanks, were shipped to Boeing in special containers fabricated to reduce the chances of further contamination of the panels, or cross-contamination between the panels.

While GC/MS as well as CAU analysis allows detection of small amounts of surface residues, we found that this approach was not ideal for the particular contaminant mix analyzed. Some of the components of the Boeing mix are not volatile, are polar, or are degraded with heat and, therefore, these components cannot be analyzed by GC/MS or CAU. Fortunately, there was a hydrocarbon peak in the contaminant mix which was easily detected by GC/MS 
and which was measured to confirm that the test panels were coated as desired.

GC/MS was able to verify contaminant concentrations on the $3 " \times 10$ " panels of $0.3 \mathrm{mg} / \mathrm{ft}^{2}, 3 \mathrm{mg} / \mathrm{ft}^{2}$, and $30 \mathrm{mg} / \mathrm{ft}^{2}$, and concentrations on the 3" 6 " panels of $3 \mathrm{mg} / \mathrm{ft}^{2}$, and $30 \mathrm{mg} / \mathrm{ft}^{2}$. Coating concentrations at $0.03 \mathrm{mg} / \mathrm{ft}^{2}$ for both size panels and at $0.3 \mathrm{mg} / \mathrm{ft}^{2}$ for the $3^{\prime \prime} \times 6 "$ panels could not be verified because the amounts of material extracted from the plates and injected into the GC/MS were below the instrument's detection limit. Results of the analyses are summarized in Table 4. These analyses could not, of course, confirm that the contaminant coating remained intact during and after shipping to Boeing.

\section{Table 4: Coating Process Details}

Data from experiments to analyze the coating process on the test panels. Each number represents the average of two data points. "NV" indicates that the concentrations of Boeing contaminants on the panels could not be verified.

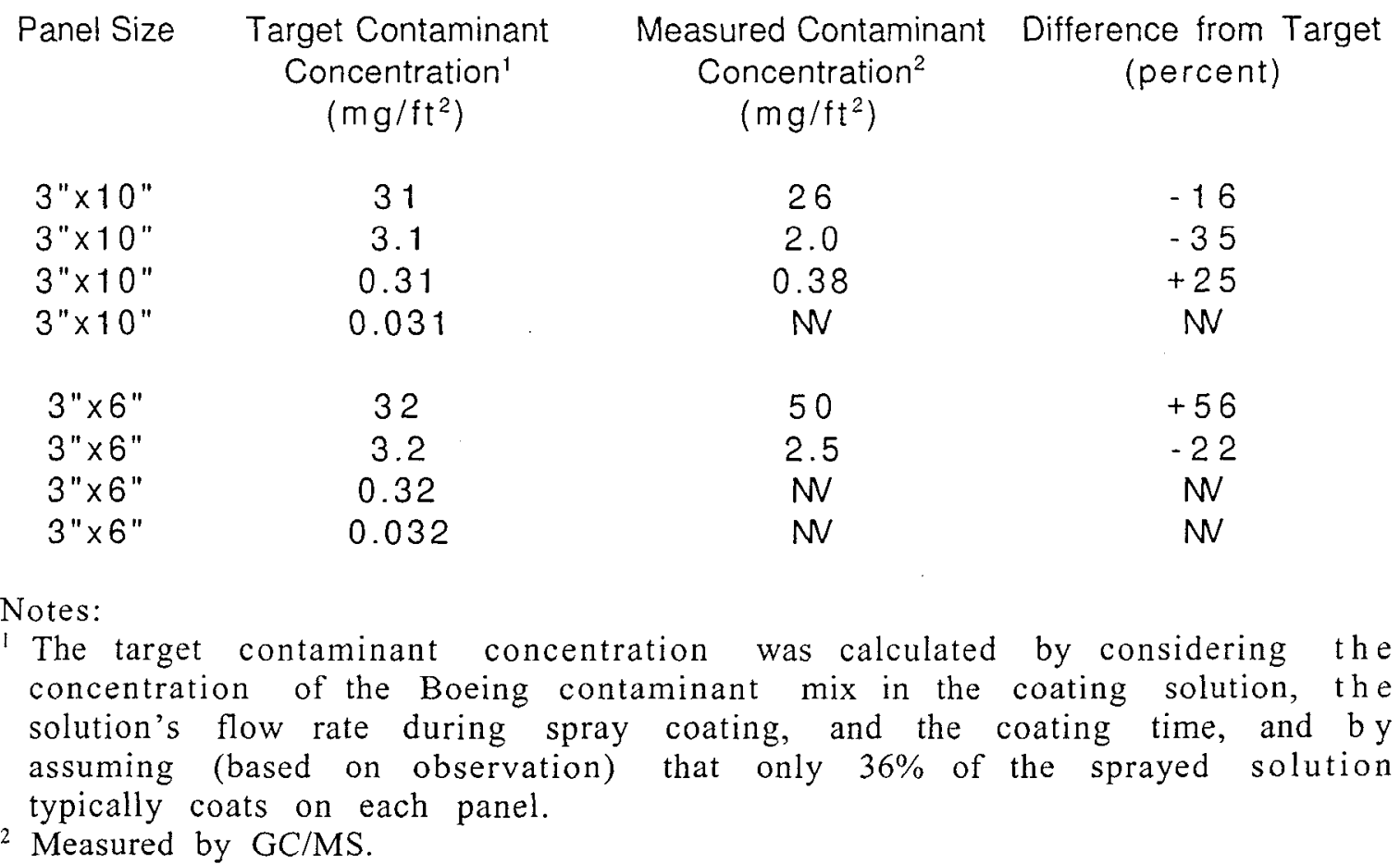




\subsection{Salt Spray Evaluation of Test Panels}

\subsection{Testing Methodology}

Neutral salt spray testing was conducted for 200 hours on 25 . of the aluminum panels that received an alodine chromate conversion coating (CCC), and 25 of the aluminum panels that received an anodic coating (AC). The testing was conducted in accordance with ASTM Designation B 117-90, Standard Test Method of Salt Spray (Fog) Testing in a laboratory environment at $70^{\circ} \mathrm{F}$ and $50 \%$ relative humidity. See Table 5 .

\section{Table 5: Salt Spray Testing Conditions}

$\begin{array}{lccccccc}\text { Process: } & \begin{array}{c}\text { Anodize } \\ \text { Only }\end{array} & \begin{array}{c}\text { Alodine } \\ \text { Prime }\end{array} & \begin{array}{c}\text { Alodine } \\ \text { Only }\end{array} & \begin{array}{c}\text { Alodine } \\ \text { Prime }\end{array} & \text { Weld } & \begin{array}{c}\text { Nonprocessed } \\ \text { Panels }\end{array} & \text { Total } \\ \text { Evaluation Technique: } & \text { Salt Spray } & \text { Adhesion } & \text { Salt Spray } & \text { Adhesion Weld Porosity } & \text { GC/MS } & \\ \text { Boeing Evaluated } & 25 & 15 & 25 & 15 & 30 & & 110 \\ \text { LLNLEvaluated } & 25 & 15 & 25 & 15 & 30 & 20 & 130 \\ \text { TOTAL } & 50 & 30 & 50 & 30 & 60 & 20 & 240\end{array}$

A polypropylene salt spray chamber fitted with a PTFE impeller pump was employed for the testing. The pump was fitted with a 0.30 " orifice spray nozzle and delivered $350 \mathrm{~mL} /$ minute of solution as spray. The solution employed was a mixture of de-ionized water and $5.0 \%$ by weight sodium chloride. The $\mathrm{pH}$ of the solution was maintained at 7.0 (measured electrometrically) through additions of sodium hydroxide or hydrochloric acid. The temperature was maintained at $90^{\circ} \mathrm{F}$, and the solution was agitated to insure salt concentration uniformity.

The panels were placed into a titanium fixture, clamped at the top and bottom, and held at an angle of 5 degrees from vertical. The testing time was 200 hours. After removal from the chamber the panels were rinsed in de-ionized water and dried. 


\subsection{Evaluation of Tests}

The surfaces of the panels were inspected for corrosion sites with the unaided eye and under $12 \mathrm{x}$ magnification, according to the following specification typically applied at LLNL for evaluating corrosion resistance:

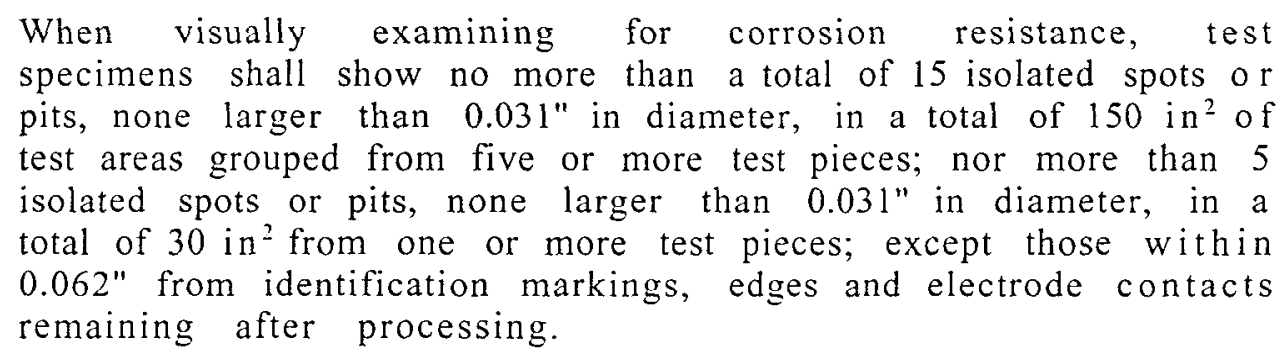

This spec was drawn from MIL-A-8625 for anodic coatings, and appears very similar to Boeing's internal specification for alodining (as transmitted by Vickie Hutsko).

Corrosion sites were identified only on the numbered side of each 3" $\mathrm{x} 10^{\prime \prime}$ panel, which is the side that was contaminated. All corrosion sites observed were less than $0.005^{\prime \prime}$ diameter. In no field of view under magnification was any pattern observed in the corrosion sites. Several panels had corrosion at the contact point of the titanium fixture; as per the above specification, these were not counted as corrosion sites.

\subsubsection{Alodined Panel results}

None of the groups of five alodined panels (each group corresponding to a particular level of contamination) passed the criterion discussed in the quotation found in the beginning of Section 4.2. In each group of five panels, the total number of allowable corrosion sites (15) was exceeded; see Table 6. There were also many panels for which the total number of allowable single-panel corrosion sites (5) was exceeded. Although the salt-spray criterion was not met for alodined panels, the relationship between number of corrosion sites and contamination level may still be useful for identifying a specification for maximum allowable contamination on the coupons. 
Toward this end, we first examined whether the average number of corrosion sites for each group of contaminated panels differed from the average number of corrosion sites on the blank panels, which served as experimental controls. Both Figure 1 and Table 6 show that there is much scatter in the data and that there is no clear trend of increasing number of corrosion sites with increasing contamination of the panels. The average number of corrosion sites observed on the pancls coated with $0,0.03,0.3,3$, and $30 \mathrm{mg} / \mathrm{ft}^{2}$ contamination were $5.4,6,7.2,6$, and 11.6, respectively. Considering the scatter in the data (see Figure 1), these numbers are comparable.

\section{Figure 1. Scatter in Data for Alodined Panels}

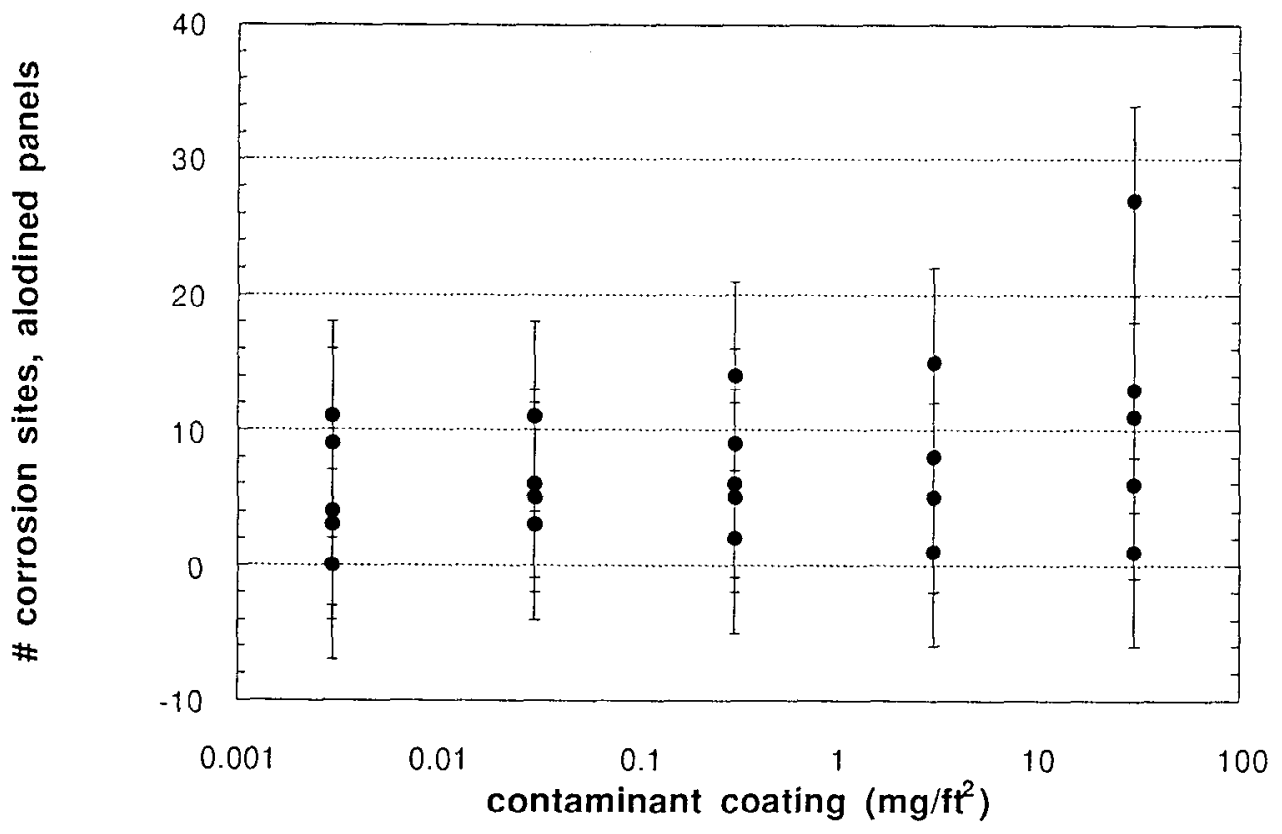


Figure 1 and Table 7 both show that the standard deviation of the number of corrosion sites on the five panels in each group is almost as large as the average number of corrosion sites for that group. This indicates that it is difficult to discern statistically significant differences in the averages. A t-test, or comparison of means, was used to determine quantitatively whether the average number of corrosions sites for a group of panels at a given contamination level was different from the average number of corrosions sitcs found on the blank (uncoated) panels ${ }^{2}$. $t$-tests showed that there was no statistically significant differences (at the $90 \%$ confidence level) between the average number of corrosion sitcs of the groups of panels contaminated with $0.03,0.3,3$, and $30 \mathrm{mg} / \mathrm{ft}^{2}$ contamination and the average number of corrosion sites of the blank panels. Thus, there is no indication from this analysis that increased levels of contamination adversely affected the alodine process.

Although the above analysis does not indicate more susceptibility to corrosion of alodined panels at higher contamination levels, one can see from Table 6 that the average number of corrosion sites for panels contaminated to $30 \mathrm{mg} / \mathrm{ft}^{2}(11.6)$ is higher than for the other groups. This higher average is largely due to the very high number of corrosion sites (27) on one of the panels coated with $30 \mathrm{mg} / \mathrm{ft}^{2}$ of contamination. We considered whether this value could be rejected as an outlier and found that based on Dixon's Q test ${ }^{3}$, it could not. Thus, we suspected that something of significance might be occurring at $30 \mathrm{mg} / \mathrm{ft}^{2}$ contamination. To examine this possibility, we decided to test the hypothesis that a) at $30 \mathrm{mg} / \mathrm{ft}^{2}$ contamination, a $\mathrm{n}$ increased number of corrosion sites form and b) the number of corrosion sites are equivalent at the other contamination levels of 0 , $0.03,0.3$, and $3 \mathrm{mg} / \mathrm{ft}^{2}$. This approach allowed us to compare the average number of corrosion sites of the panels coated with 30 $\mathrm{mg} / \mathrm{ft}^{2}$ contamination and the average number of corrosion sites found on all of the other panels (see Table 7 for the results of this analysis).

${ }^{2}$ Statistics for Analytical Chemistry, 2nd Edition, by J. C. Miller and J. N. Miller, Ellis Horwood Series in Analytical Chemistry, Ellis Horwood Limited, England, 1988 , pp. $55-56$.

${ }^{3}$ Statistics for Analytical Chemistry, 2nd Edition, by J. C. Miller and J. N. Miller, Ellis Horwood Series in Analytical Chemistry, Ellis Horwood Limited, England, 1988, pp. 62-65.

Project Summary Rev 9

$2 / 4 / 99$

Page 13 
As Table 7 shows, t-tests suggest that these two averages arc statistically different at the $90 \%$ confidence level. In other words, the probability of such a difference in the means arising purely by chance is only $10 \% .^{2}$ So the question arises, are we secing a degradation of alodining quality for contamination levels of 30 $\mathrm{mg} / \mathrm{ft}^{2}$ ?

Table 7 indicates that when the average number of corrosion sites for other groups of panels (those contaminated at 3 and $0.3 \mathrm{mg} / \mathrm{ft}^{2}$ ) are compared with the average number of corrosion sites for groups of panels at lower concentrations levels, no statistically significant differences in their averages are observed.

As mentioned above, the mean number of corrosion sites for panels coated at $0.03,0.3,3$, and $30 \mathrm{mg} / \mathrm{ft}^{2}$ contamination are not statistically different from the mean number of corrosion sites observed on the blank panels. This suggests that either there is no correlation between the number of corrosion sites and the contamination level, or, if such a correlation does exist, a much larger data set would be required in order to be able to discern differences in the data. On the other hand, the observation of a significant difference when the number of corrosion sites observed on the alodined panels coated at $30 \mathrm{mg} / \mathrm{ft}^{2}$ contamination is compared to the average number of corrosion sites on all of the other panels indicates that something might be occurring which merits further investigation. 
Table 6: Corrosion Data

\section{Contamination Alodined Panels} Level

\begin{tabular}{|c|c|c|c|c|c|c|c|}
\hline & & $\#$ & $\begin{array}{c}\text { Corrosion } \\
\text { Sites }\end{array}$ & Average & \# & $\begin{array}{c}\text { Corrosion } \\
\text { Sites }\end{array}$ & Average \\
\hline \multirow{5}{*}{\multicolumn{2}{|c|}{ Blank }} & 86 & 0 & & 103 & 2 & \\
\hline & & 87 & 4 & & 105 & 1 & \\
\hline & & 88 & 11 & & 106 & 3 & \\
\hline & & 89 & 9 & & 107 & 1 & \\
\hline & & 90 & 3 & 5.4 & 109 & 1 & 1.6 \\
\hline \multirow[t]{5}{*}{0.03} & $\mathrm{mg} / \mathrm{ft}^{2}$ & 153 & 11 & & 126 & 0 & \\
\hline & & 155 & 6 & & 127 & 2 & \\
\hline & & 156 & 5 & & 128 & 0 & \\
\hline & & 157 & 5 & & 129 & 0 & \\
\hline & & 158 & 3 & 6 & 130 & 2 & 0.8 \\
\hline \multirow[t]{5}{*}{0.3} & $\mathrm{mg} / \mathrm{ft}^{2}$ & 191 & 6 & & 173 & 3 & \\
\hline & & 192 & 5 & & 175 & 2 & \\
\hline & & 193 & 2 & & 176 & 0 & \\
\hline & & 195 & 14 & & 177 & 0 & \\
\hline & & 196 & 9 & 7.2 & 178 & 0 & 1 \\
\hline \multirow[t]{5}{*}{3} & $\mathrm{mg} / \mathrm{ft}^{2}$ & 211 & 1 & & 229 & 0 & \\
\hline & & 212 & 15 & & 230 & 4 & \\
\hline & & 213 & 1 & & 231 & 2 & \\
\hline & & 215 & 8 & & 232 & 0 & \\
\hline & & 216 & 5 & 6 & 233 & 0 & 1.2 \\
\hline & $\mathrm{mg} / \mathrm{ft}^{2}$ & 259 & 27 & & 302 & 1 & \\
\hline & & 260 & 13 & & 303 & 0 & \\
\hline & & 261 & 11 & & 305 & 0 & \\
\hline & & 262 & 1 & & 306 & 0 & \\
\hline & & 263 & 6 & 11.6 & 307 & 2 & 0.6 \\
\hline
\end{tabular}

Notes:

\section{Anodized Panels}
\# Corrosion Average Sites

.

(1) 


\section{Table 7: Statistical Analyses of Alodined Panel Data}

\begin{tabular}{|c|c|c|c|c|c|c|}
\hline \multirow[t]{2}{*}{$\begin{array}{c}\text { Contam. } \\
\text { level }\end{array}$} & \multirow[t]{2}{*}{$\begin{array}{c}\text { Avg. \# } \\
\text { corrosion } \\
\text { sites }\end{array}$} & \multirow[t]{2}{*}{$\begin{array}{l}\text { Std. } \\
\text { dev. } \\
\text { of } \\
\text { avg. }\end{array}$} & \multicolumn{2}{|c|}{$\begin{array}{l}\text { Stat. significance } \\
\text { btween avg. number } \\
\text { of corrosion sites on } \\
\text { contaminated plates } \\
\text { and blanks? }\end{array}$} & \multicolumn{2}{|c|}{$\begin{array}{l}\text { Stat. significance } \\
\text { btween avg. number of } \\
\text { corrosion sites on } \\
\text { contaminated plates } \\
\text { and average of all } \\
\text { other plates of lower } \\
\text { contam levels? }\end{array}$} \\
\hline & & & $\begin{array}{c}\text { Calc'd } \\
t-v a l u e\end{array}$ & $\begin{array}{l}\text { Significant } \\
@ 90 \% \\
\text { confidence } \\
\text { level? }{ }^{1} \\
\end{array}$ & $\begin{array}{l}\text { Calc'd } \\
\text { t-value }\end{array}$ & $\begin{array}{c}\text { Significant } \\
@ 90 \% \\
\text { confidence } \\
\text { level? }\end{array}$ \\
\hline blank & 5.4 & 4.5 & $\ldots$ & $\ldots \ldots$ & 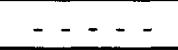 & $\ldots \ldots$ \\
\hline 0.03 & 6 & 9.8 & 0.50 & $\mathrm{No}$ & $\ldots \ldots$ & $\ldots .$. \\
\hline 0.3 & 7.2 & 5.8 & 0.42 & No & 0.70 & $\mathrm{No}^{2}$ \\
\hline 3 & 6 & 4.5 & 1.70 & $\mathrm{No}$ & 0.09 & $\mathrm{No}^{3}$ \\
\hline 30 & 11.6 & 7.6 & 1.28 & No & 1.96 & $Y_{e s}^{4}$ \\
\hline
\end{tabular}

Notes:

${ }^{1}$ difference of means is significant only if the calculated $t$-statistic exceeds the critical value of $|t|$ at the $90 \%$ significance level for 8 degrees of freedom (1.86).

2 compared to critical value of $|t|$ at the $90 \%$ significance level for 12 degrees of freedom (1.78) and 14 degrees of freedom (1.76).

${ }^{3}$ compared to critical value of $|t|$ at the $90 \%$ significance level, 18 degrees of freedom (1.73).

${ }^{4}$ compared to critical value of $|t|$ at the $90 \%$ significance level for 20 degrees of freedom (1.72) and for 30 degrees of freedom (1.70).

\subsubsection{Anodized Panel Results}

All of the groups of five anodized panels (corresponding to a particular contamination level), each with a $30 \mathrm{in}^{2}$ area, passed the criterion described in Section 4.2. Panels coated with $0,0.03,0.3,3$, and $30 \mathrm{mg} / \mathrm{ft}^{2}$ contamination were marked with an average of 1.6 , $0.8,1,1.2$, and 0.6 corrosion sites, respectively; see Table $6 . \Lambda \mathrm{s}$ with the alodined panel data, the values for the standard deviations of the average number of corrosion sites for each panel group were as large as the values of the average number of corrosion sites for the group. This suggests much scatter in the data. 
Statistical analyses were performed for the anodized panels; see Table 8 . At the $90 \%$ significance level, no differences were observed between the average number of corrosions sites on the panels that were coated with $0.03,0.3,3$, and $30 \mathrm{mg} / \mathrm{ft}^{2}$ contamination and the average number of corrosion sites on the blank panels. In addition, comparison of the average number of corrosion sites for a group of panels against the average number of corrosion sites for all of the panels coated at lower contaminant concentrations (including the blanks) showed no statistical difference. Therefore, a specification for allowable contamination does not appear to be suggested by the data on anodized panels.

\section{$\underline{5.0 \quad \text { Adhesion Tests }}$}

Pull-off adhesion testing was conducted on 25 aluminum panels that were primer coated over an alodine chromate conversion coating. Adhesion testing was also performed on 25 aluminum panels that were primer coated over an anodized coating.

The testing was conducted in accordance with ASTM Standard D 4541 in a laboratory environment with $70^{\circ} \mathrm{F}$ controlled temperature and $50 \%$ relative humidity. $\Lambda \mathrm{n}$ INSTRON model 4200 adhesion tester, fitted with a $5,000 \mathrm{~kg}$ load cell, was used. A base retainer was fitted to the model 4200 , and a threaded connector on a swivel mount was fitted to the movable cross head. The speed of the movable cross head was $0.02 " /$ minute. The electronic load cell was electronically calibrated and manually tested with steel weights. Pull stubs of $0.750^{\prime \prime}$ diameter were attached to the substrate with HYSOL 907 adhesive.

Given the minimal substrate thickness, there was concern that flexing of the substrate would adversely affect adhesion of the pull stubs, and that the measurements taken would not accurately reflect the actual adhesion without flexing. After the first two measurements were taken (on panels 91 and 92), backing plates of 6061 aluminum (0.25" thick) were bonded to the opposite sides of the plates. Note in Table 9 the order of magnitude increase in adhesion values after this was done. 


\section{Table 8: Statistical Analyses of Anodized Panel Data}

\begin{tabular}{|c|c|c|c|c|c|c|}
\hline \multirow[t]{2}{*}{$\begin{array}{c}\text { Contam. } \\
\text { level }\end{array}$} & \multirow[t]{2}{*}{$\begin{array}{c}\text { Avg. \# } \\
\text { corrosion } \\
\text { sites }\end{array}$} & \multirow[t]{2}{*}{$\begin{array}{l}\text { Std. } \\
\text { dev. } \\
\text { of } \\
\text { avg. }\end{array}$} & \multicolumn{2}{|c|}{$\begin{array}{l}\text { Stat. significance } \\
\text { btween avg. number } \\
\text { of corrosion sites on } \\
\text { contaminated plates } \\
\text { and blanks? }\end{array}$} & \multicolumn{2}{|c|}{$\begin{array}{l}\text { Stat. significance } \\
\text { btween avg. number of } \\
\text { corrosion sites on } \\
\text { contaminated plates } \\
\text { and average of all } \\
\text { others of lower contam } \\
\text { levels? }\end{array}$} \\
\hline & & & $\begin{array}{c}\text { Calc'd } \\
t-\text { value }\end{array}$ & $\begin{array}{c}\text { Significant } \\
@ 90 \% \\
\text { confidence } \\
\text { level? }\end{array}$ & $\begin{array}{l}\text { Calc'd } \\
t-v a l u e\end{array}$ & $\begin{array}{c}\text { Significant } \\
@ 90 \% \\
\text { confidence } \\
\text { level? }\end{array}$ \\
\hline blank & 1.6 & 0.90 & $\ldots \ldots$ & $\ldots$. & $\ldots \ldots$ & $\ldots \ldots$ \\
\hline 0.03 & 0.8 & 1.1 & 1.06 & $\mathrm{No}$ & $-\cdots$ & 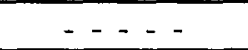 \\
\hline 0.3 & 1.0 & 1.4 & 0.22 & $\mathrm{No}$ & 0.14 & $\mathrm{No}^{2}$ \\
\hline 3 & 1.2 & 1.8 & 0.27 & $\mathrm{Nb}$ & 0.20 & $\mathrm{No}^{3}$ \\
\hline 30 & 0.6 & 0.90 & 1.26 & $\mathrm{No}$ & 0.50 & $\mathrm{No}^{4}$ \\
\hline
\end{tabular}

Notes:

${ }^{1}$ difference of means is significant only if the calculated $t$-statistic exceeds the critical value of $|t|$ at the $90 \%$ significance level for 8 degrees of freedom (1.86).

2 compared to critical value of $|t|$ at the $90 \%$ significance level for 12 degrees of freedom (1.78) and 14 degrees of freedom (1.76).

${ }^{3}$ compared to critical value of $|t|$ at the $90 \%$ significance level, 18 degrees of freedom (1.73).

${ }^{4}$ compared to critical value of $|t|$ at the $90 \%$ significance level for 20 degrees of freedom (1.72) and for 30 degrees of freedom (1.70). 


\section{Table 9: Adhesion Testing Data}

\begin{tabular}{|c|c|c|c|c|c|}
\hline Contamination & Surface & Panel & Adhesion $^{3}$ & Average & Break Occurred \\
\hline Level & Treatment ${ }^{1}$ & Number ${ }^{2}$ & $(P S I)$ & Adhesion ${ }^{4}$ & Predominantly Between \\
\hline Blank & alodine & 91 & 437 & & primer and epoxy \\
\hline & alodine & 92 & 350 & & primer and epoxy \\
\hline & alodine & 93 & 3936 & 3936 & primer and epoxy \\
\hline & anodize & 110 & 3645 & & treatment layer and primer \\
\hline & anodize & 111 & 3965 & & primer and epoxy \\
\hline & anodize & 112 & 3003 & 3538 & treatment layer and primer \\
\hline $0.03 \mathrm{mg} / \mathrm{ft}^{2}$ & anodize & 131 & 3207 & & treatment layer and primer \\
\hline & anodize & 132 & 3295 & & treatment layer and primer \\
\hline & anodize & 133 & 3980 & 3494 & alum substrate and treatment lay \\
\hline & alodine & 160 & 3586 & & primer and epoxy \\
\hline & alodine & 161 & 3965 & 3776 & treatment layer and primer \\
\hline $0.3 \mathrm{mg} / \mathrm{ft}^{2}$ & anodize & 179 & 2974 & & primer and epoxy \\
\hline & anodize & 180 & 3933 & & primer and epoxy \\
\hline & anodize & 181 & 2508 & 3138 & primer and epoxy \\
\hline & alodine & 197 & 3499 & & primer and epoxy \\
\hline & alodine & 198 & 3411 & & primer and epoxy \\
\hline & alodine & 199 & 4006 & 3639 & primer and epoxy \\
\hline $3 \mathrm{mg} / \mathrm{ft}^{2}$ & alodine & 217 & 4000 & & primer and epoxy \\
\hline & alodine & 218 & 3295 & & primer and epoxy \\
\hline & alodine & 219 & 3878 & 3724 & primer and epoxy \\
\hline & anodize & 235 & 2770 & & primer and epoxy \\
\hline & anodize & 236 & 3353 & & primer and epoxy \\
\hline & anodize & 237 & 3998 & 3374 & $\begin{array}{l}\text { treatment layer and primer } \\
\text { and primer and epoxy }\end{array}$ \\
\hline $30 \mathrm{mg} / \mathrm{ft}^{2}$ & alodine & 265 & 3499 & & primer and epoxy \\
\hline & alodine & 266 & 3178 & & primer and epoxy \\
\hline & alodine & 267 & 3980 & 3552 & primer and epoxy \\
\hline & anodize & 308 & 3980 & & treatment layer and primer \\
\hline & anodize & 309 & 3382 & & treatment layer and primer \\
\hline & anodize & 310 & 3411 & 3591 & treatment layer and primer \\
\hline
\end{tabular}

Notes:

1. All panels were primered on top of surface treatment layer.

2. Only panels $\underline{91}$ and $\underline{92}$ have no backing plates. Note their reduced adhesion.

3. Adhesion testing was conducted per ASTM D 4541.

4. Average for a particular contamination level and type of surface treatment. Note that panels 91 and 92 are not included in average (no backing plates). 
Adhesion values in pounds per square inch (PSI) were calculated using the formula $4 \mathrm{~F} / \pi \mathrm{d}^{2}$, where " $\mathrm{F}$ " is the breaking force in pounds and "d" is the stub diameter in inches. Table 9 identifies between which layers the failure predominantly occurred. Figure 2 depicts a sample in which the failure occurred between the primer and epoxy and between the surface treatment layer and primer.

\section{Figure 2. Adhesion Failure}

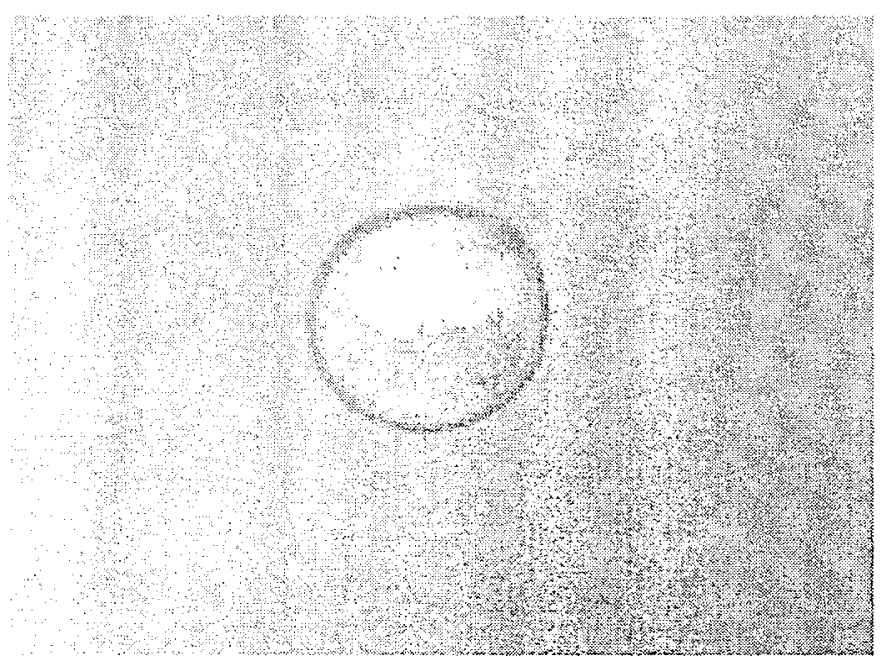

Figure 3 shows a comparison of adhesion values obtained for the alodined and anodized panels which were treated with different levels of contamination. Because of the small number of replicates, these data were not analyzed by $t$-test. The overall average of adhesion values for the alodined and anodized panels (of all contamination levels) were approximately 3700 PSI and 3400 PSI, respectively. Given the measurement error, adhesion values for both the alodined and anodized panels were equivalent; see Figure 3. In addition, average adhesion values did not change with changing contaminant levels. 


\section{Figure 3. Comparison of Adhesion Data for}

Alodined and Anodized Panels

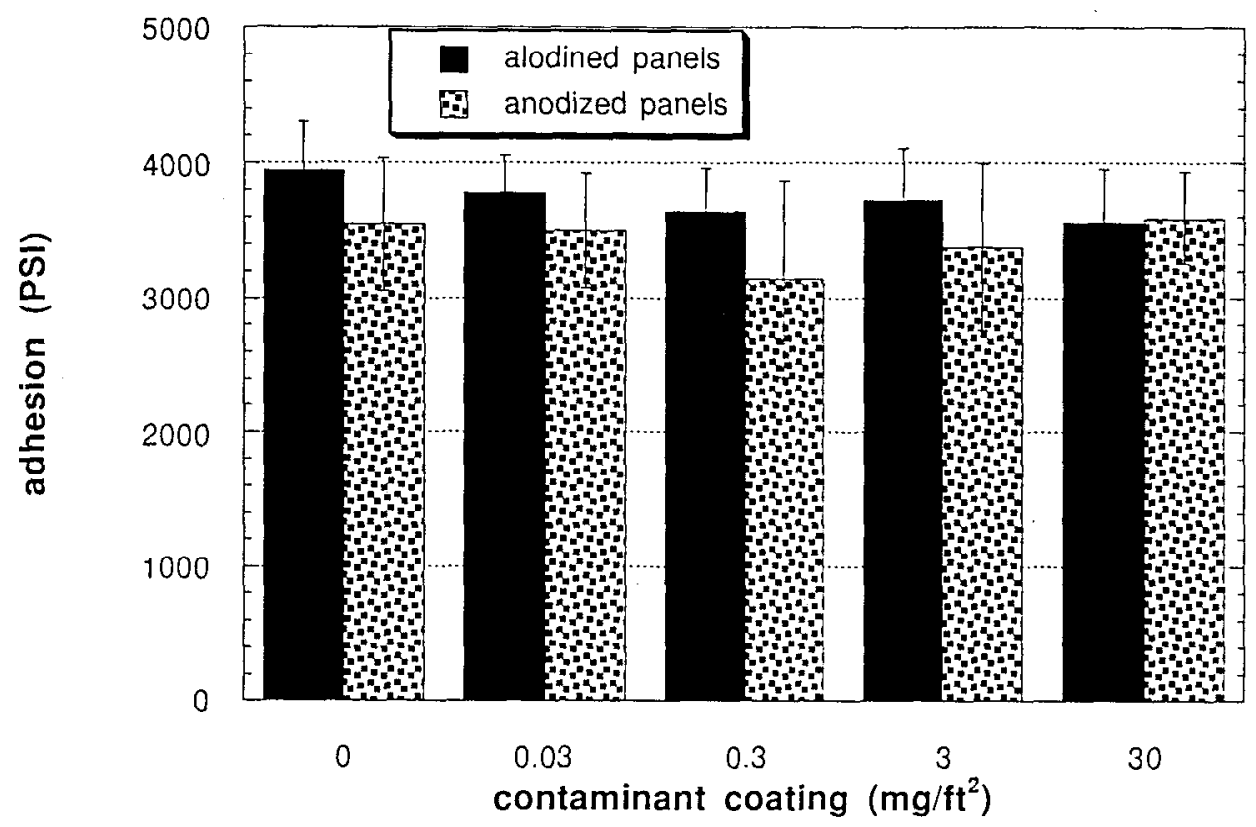

Notes:

1. Each bar represents the average of either two or three values. The only exception is that the bar representing the adhesion value for the blank alodined panel represents only one measurement (measurements for the unbacked plates were not included).

2. Error bars represent $+/$ - the standard deviation of each average measurement. The error bar for the blank alodined panel average was estimated by averaging the standard deviations obtained for the averages of all other levels of coatings of the alodined panels.

\subsection{Weld Porosity Analysis}

\subsection{Radiographic Inspection}

Radiographic (x-ray) inspection was performed on 15 aluminum coupon pairs welded together. The following parameters were used in the inspection: $35 \mathrm{kV}, 10 \mathrm{~mA}$, and 1.8 minutes exposure using Kodak "M" ready pack film.

Upon examination, it was determined that, of the welds on the 15 coupon pairs $\mathrm{x}$-rayed, only 6 contained significant porosity (i.e. 
inclusions of 0.01 " diameter or larger). The results are listed in Table 11. While results are irregular with respect to contamination levels, the average number of inclusions for coupon pairs contaminated with

\section{Table 11. Radiographic Analysis Results}

\begin{tabular}{|c|c|c|c|c|c|}
\hline Cont & $\begin{array}{l}\text { amination } \\
\text { Level }\end{array}$ & $\begin{array}{l}\text { Coupon } \\
\text { Pair }\end{array}$ & $\begin{array}{l}\text { Number of } \\
\text { Inclusions }\end{array}$ & $\begin{array}{l}\text { Average } \\
\text { Inclusions }\end{array}$ & Size Range \\
\hline & Blank & $587 / 588$ & 1 & & $0.012^{\prime \prime}$ \\
\hline & & $589 / 590$ & 4 & & $0.01 "$ to $0.015^{\prime \prime}$ \\
\hline & & $591 / 592$ & 0 & 1.67 & \\
\hline 0.03 & $\mathrm{mg} / \mathrm{ft}^{2}$ & $507 / 508$ & 0 & & \\
\hline & & $509 / 510$ & 0 & & \\
\hline & & $511 / 512$ & 0 & 0.00 & \\
\hline 0.3 & $\mathrm{mg} / \mathrm{ft}^{2}$ & $518 / 519$ & 0 & & \\
\hline & & $520 / 521$ & 0 & & \\
\hline & & $522 / 523$ & 2 & 0.67 & $0.012 "$ each \\
\hline 3 & $\mathrm{mg} / \mathrm{ft}^{2}$ & $531 / 532$ & 0 & & \\
\hline & & $533 / 535$ & 0 & & \\
\hline & & $536 / 537$ & 0 & 0.00 & \\
\hline 30 & $\mathrm{mg} / \mathrm{ft}^{2}$ & $563 / 565$ & 3 & & $0.012^{\prime \prime}$ each \\
\hline & & $566 / 567$ & 2 & & $0.015^{\prime \prime}$ each \\
\hline & & $568 / 569$ & 6 & 3.67 & $0.01 "$ to $0.03^{\prime \prime}$ \\
\hline
\end{tabular}

$30 \mathrm{mg} / \mathrm{ft}^{2}$ of soil (3.7) is higher than for coupon pairs with other contamination levels, whose average inclusions range from 0 to 1.7. However, as seen in Figure 4, the measurement error bars are large compared with the average values for the number of inclusions and, thus, it is not clear whether the differences in averages are statistically significant.

In order to gauge the significance of the difference in means between the coupon pairs contaminated to a level of $30 \mathrm{mg} / \mathrm{ft}^{2}$ and all other coupon pairs, a $t$-test was done. The analysis indicates that, at the $99 \%$ confidence level, the difference in the average number of Project Summary Rev 9 
inclusions in the welds of coupon pairs contaminated to $30 \mathrm{mg} / \mathrm{ft}^{2}$ and the average number of inclusions in the welds on all other coupon pairs is statistically significant. However, given the scatter in the data and the fact that there were several "zero" average values, this finding should only be interpreted to mean that there is a possibility of weld quality falling off due to increased contamination levels, and that further investigation may be merited.

Figurc 4. Radiographic Data

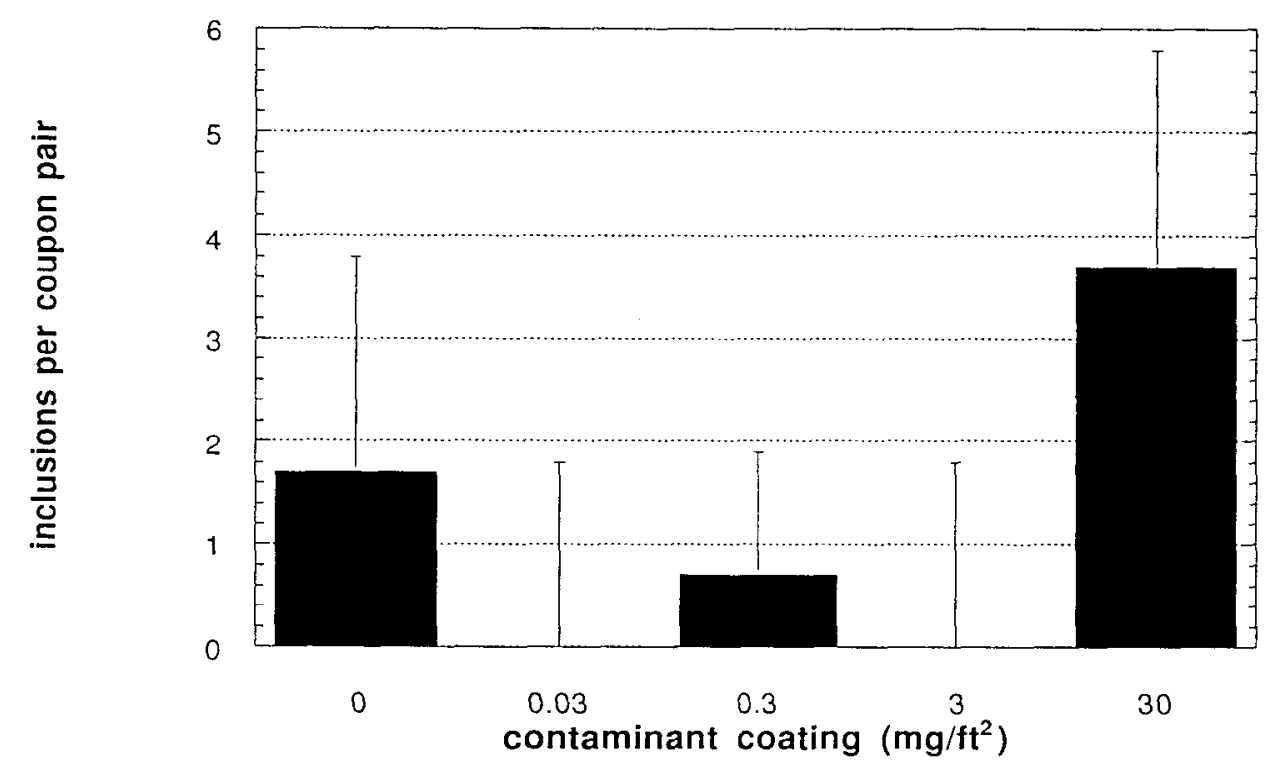

Notes:

1. Each bar represents the average of three values.

2. Error bars represent $+/-$ the standard deviation of each average measurement. The error bars for the $0.03 \mathrm{mg} / \mathrm{ft}^{2}$ and $3 \mathrm{mg} / \mathrm{ft}^{2}$ panel averages were estimated by averaging the standard deviations obtained for the averages of all other levels of contamination.

\subsection{UItrasonic Inspection}


Fifteen welded aluminum plates were ultrasonically inspected using a contact angle beam technique. A $5 \mathrm{MHz}$ transducer with an angle beam wedge giving a 67 degree sound beam through the weld volume was used to scan the plates. A Sonic Mk IV ultrasonic tester was used. A 0.060" diameter side drilled hole in an aluminum test block was used as a reference. No detectable reflection signals were noted other than from weld crown and root roughness. The weld between plates 566 and 567 has a small root subsidence that did not show ultrasonically. A highfrequency automated immersion scan may show smaller details if a more comprehensive study is needed.

\subsection{Conclusions}

The aim of this project was to perform preliminary analyses of aluminum substrates as a first, "Phase 0 " step in determining suitable cleanliness criteria for actual Boeing parts made from this material. A wide spread of contamination levels was specified for the Phase 0 test coupons, in the hopes of finding a range in which an appropriate cleanliness specification might lie. It was planned that, based on the results of the Phase 0 testing, more detailed analyses ("Phase 1 testing") would be performed in order to more accurately identify appropriate criteria.

Most of the Phase 0 data are inconclusive. Two of the analyses hint that, for parts that will be alodined or welded, an appropriate maximum contamination level might lie between 3 and $30 \mathrm{mg} / \mathrm{ft}^{2}$. Further testing, with a larger data set to allow better statistical analyses, is needed to confirm this and determine whether this is the correct range in which the criteria should be set. 